\title{
Sexualidade do adolescente na percepção dos pais, sob a perspectiva de Foucault
}

\author{
Adolescent Sexuality from the father's view, according to Foucault's perspective
}

Sexualidad del adolescente en la percepción de los padres, bajo la perspectiva de Foucault

Renata Salomão1, Marta Angélica lossi Silva², Maria Aparecida Tedeschi Cano ${ }^{3}$

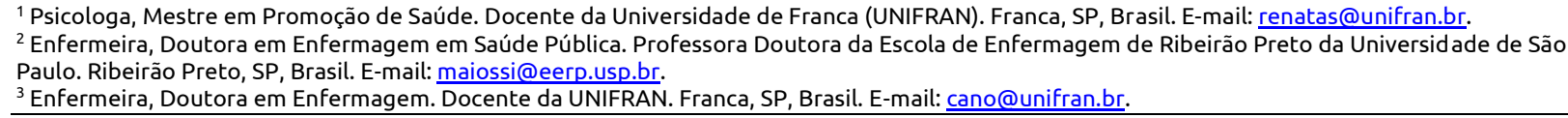

\section{RESUMO}

O presente trabalho teve como objetivo conhecer junto a pais de adolescentes do sexo masculino como tem sido sua experiência com a sexualidade de seus filhos e também como era o relacionamento nesse aspecto com os seus pais quando eram adolescentes. Pesquisa de abordagem qualitativa realizada com quatro pais de alunos de uma escola privada do município de Franca, SP, utilizando-se de entrevistas semiestruturadas que foram tratadas na perspectiva da análise de conteúdo, modalidade temática. Após a leitura, organização e ordenação dos dados estabeleceram-se, com base na perspectiva de Foucault, dois núcleos temáticos: contextualização da época da adolescência e controle da sexualidade, com os subtemas diálogo, medicalização e religião. Observou-se na análise que o aparente afrouxamento da repressão sexual pode ser um engodo, já que sistemas mais sutis de controle podem ser utilizados para manipular com maior precisão a sexualidade do adolescente.

Descritores: Adolescente; Sexualidade; Educação Sexual.

\section{ABSTRACT}

The objective of this study was to learn, with fathers of male adolescents, their son's experience with sexuality, and what the relationship with their own father was like in this regard. This qualitative study was performed with four fathers of students of a private school in Franca, São Paulo, Brazil. Semi-structured interviews were performed and submitted to thematic content analysis. After reading and organizing the data, two central themes were established based on Foucault's perspective: contextualization of the period of adolescence and control over sexuality, with the subthemes dialogue, medicalization and religion. In the analysis, it was observed that the apparent loosened sexual repression may be a delusion, as there are more subtle control systems that can be used to manipulate the adolescent's sexuality with greater precision.

Descriptors: Adolescent; Sexuality; Sex Education.

\section{RESUMEN}

El trabajo objetivó conocer junto con padres de adolescentes de sexo masculino, cómo ha sido su experiencia con la sexualidad de sus hijos, y también cómo era la relación en ese tema con sus padres cuando eran adolescentes. Investigación cualitativa, realizada con cuatro padres de alumnos de escuela privada de Franca-SP, utilizándose entrevistas semiestructuradas, tratadas en la perspectiva del análisis de contenido, modalidad temática. Luego de la lectura, organización y ordenamiento de los datos, se establecieron, con base en la perspectiva de Foucault, dos núcleos temáticos: contextualización de la época de la adolescencia y control de la sexualidad, con los subtemas diálogo, medicalización y religión. Se observó en el análisis que la aparente relajación de la represión sexual puede constituir un engaño, ya que pueden utilizarse sistemas más sutiles de control para manipular con mayor precisión la sexualidad del adolescente.

Descriptores: Adolescente; Sexualidad; Educación Sexual. 


\section{INTRODUÇÃO}

$\mathrm{Na}$ adolescência ocorrem três fenômenos importantes do desenvolvimento humano: a puberdade, com o amadurecimento sexual e reprodutor; a passagem da infância para a vida adulta e a estruturação de uma identidade definida.

As modificações físicas constituem a parte da adolescência denominada puberdade, caracterizada principalmente pela aceleração e desaceleração do crescimento físico, e pelas mudanças na composição corporal e eclosão hormonal com a evolução da maturação sexual, podendo esta última ser acompanhada do desenvolvimento de caracteres sexuais secundários masculinos e femininos ${ }^{(1)}$.

Pelas próprias características físicas e emocionais que vivenciam nesta fase da vida, os adolescentes ficam expostos a um conjunto de aspectos não apenas individuais, mas também coletivos e contextuais, que acarretam maior vulnerabilidade e, de modo inseparável, maior ou menor disponibilidade de recursos de todas as ordens para se proteger (2).

Uma análise da vulnerabilidade dos adolescentes envolve a avaliação articulada de três eixos: componente individual, que diz respeito ao grau e a qualidade da informação que eles dispõem sobre o risco, a capacidade de elaborar e incorporar as informações aos seus cotidianos de preocupações e interesses, e às possibilidades efetivas de transformar essas preocupações em práticas protegidas e protetoras; componente social, que diz respeito à obtenção, assimilação e incorporação de informação, que dependem não apenas deles, mas também do acesso a meios de comunicação, escolarização, disponibilidade de recursos materiais, possibilidade de enfrentar barreiras culturais, estar livre e poder defender-se de coerções violentas, entre outras; e componente programático, que envolve a existência efetiva e democrática de recursos sociais de que necessitam para se proteger de danos ${ }^{(2)}$.

Características do comportamento, presentes em maior ou menor grau, e a experiência sexual cada vez mais precoce, vem juntamente com uma utilização reduzida de métodos preventivos nas primeiras e nas subsequentes relações sexuais, tendo como consequências a maternidade e a paternidade prematuras, assim como o risco de uma DST/Aids ${ }^{(3)}$.

Quando recorremos à literatura correspondente, observamos que o foco de atenção dos pesquisadores em relação à sexualidade está voltado para o gênero feminino e para as questões referentes à maternidade ${ }^{(4-}$ 8). Nesse sentido, é essencial vislumbrar o adolescente masculino, e proporcionar-lhe a mesma atenção oferecida às adolescentes. Os serviços de saúde devem, por exemplo, promover de forma igualitária ações educativas e preventivas em relação à DST, gravidez precoce e paternidade.

Desta forma buscamos nessa pesquisa focalizar para os aspectos da sexualidade na adolescência envolvendo a questão de gênero, delineando assim o objeto de estudo a partir da percepção dos pais de adolescentes do sexo masculino sobre a sua sexualidade e a de seu filho.

Foucault ${ }^{(9)}$ nos mostrou com clareza que a repressão da sexualidade muda de instâncias de poder de onde provêm, mas não deixa de existir. Com base nesse referencial entendemos que houve uma abertura na sociedade atual, para que os filhos falem mais de sexo com seus pais, o que em um primeiro momento se apresenta como um afrouxamento da repressão sexual, mas que, se analisado com maior profundidade pode nos remeter à uma repressão mais sutil e portanto mais perigosa e eficaz.

Na atualidade, os pesquisadores se reportam à família como uma referência na vida dos adolescentes, principalmente, quando se pensa na orientação à sexualidade ${ }^{(10-12)}$. A preocupação com os filhos, a forma de orientá-los e as maneiras de conduzi-los com segurança nunca estiveram tão presentes na pauta das discussões como nos dias atuais.

Hoje os pais estão preocupados ou, pelo menos mais interessados, em conseguir manter um diálogo com seus filhos. Não se pode ignorar que a AIDS, as doenças sexualmente transmissíveis e as drogas são molas propulsoras para uma nova possibilidade de relacionamento entre pais e filhos ${ }^{(13)}$.

Entendemos que todo o interesse de diferentes pesquisadores e dos próprios pais ao redor da família nos indica que ela continua sendo a célula fundamental da sociedade, a matriz do desenvolvimento psicossocial de seus membros e a que determina a estes o cunho da individualidade.

Por outro lado, tanto para homens como para mulheres, a educação sexual sempre foi ostensivamente repressora. As regras sociais, em muitos casos ainda vigentes, valorizam a fidelidade e o casamento como contextos para o início da vida sexual. Reforçam uma 
hierarquia de comportamentos desigual e diferente para meninas e meninos, por expectativas desiguais de gênero, estabelecendo, por exemplo, para as meninas a abstinência sexual durante a adolescência e estabelecendo por vezes que deveriam ter suas relações sexuais, com o noivo, no matrimônio ou por amor. Ao contrário, para os meninos não especificam o tipo de vínculo e nem a motivação para tal, sendo em sua maioria regras muito mais permissivas ${ }^{(11,14)}$

Posto isso, o presente trabalho teve como objetivo conhecer, junto a pais de adolescentes do sexo masculino, como tem sido sua experiência com a sexualidade de seus filhos, e também como era o relacionamento nesse aspecto com os seus pais quando eram adolescentes.

\section{MÉTODOS}

No presente estudo adotamos a abordagem qualitativa como alternativa metodológica. O método qualitativo é aquele que se aplica ao estudo das relações, das representações, das crenças, opiniões e percepções, produtos das interpretações que os sujeitos fazem no tocante a si mesmos, ao seu contexto vivido, permitindo desvelar processos sociais referentes a grupos particulares, valorizando a "objetivação"(15)

Esta investigação foi realizada na cidade de Franca/SP, localizada na região noroeste do Estado de São Paulo, tendo como sujeitos de pesquisa, intencionalmente, pais de uma escola privada de ensino médio. Esta escolha embasou-se na afirmativa de que a pesquisa qualitativa trabalha com pessoas e atores sociais, em relação a grupos sociais(15). Partindo do pressuposto de que o grupo ideal de sujeitos a ser investigado é aquele capaz de refletir a totalidade e os atributos do objeto de estudo que se pretende conhecer, propôs-se então privilegiar pais de adolescentes do sexo masculino e alunos de escola privada. Foram efetuadas entrevistas em número suficiente para permitir certa reincidência de informação e garantir que estas contivessem o conjunto das experiências e expressões dos vários elementos informantes.

Os pais foram contactados e informados previamente, por meio de telefonema, sobre os objetivos da pesquisa e também sobre a necessidade de gravação das entrevistas. Após a sua aceitação, foram agendados dias e horários para a realização das mesmas. Foram entrevistados quatro pais de adolescentes que espontaneamente concordaram em participar do estudo.
As entrevistas foram realizadas na residência, por meio de visitas domiciliárias.

O roteiro da entrevista contemplou as seguintes questões norteadoras: 1) Fale-me sobre sua adolescência e como eram discutidas as questões de sexualidade; 2 ) Como foi a participação de seu pai na sua adolescência?; 3) Como você vê a adolescência de seu filho e as questões de sexualidade? E como tem sido sua participação nesse processo?

O grupo de sujeitos não buscou privilegiar uma representatividade numérica e sim um aprofundamento da temática e a capacidade de refletir a totalidade do fenômeno nas suas múltiplas dimensões(15). Neste sentido, o total das entrevistas individuais foi alcançado, considerando-se a representatividade da amostra a partir da sua saturação ${ }^{(16)}$. Os entrevistados foram identificados como atores sociais, e quando citados na análise de dados usamos a seguinte designação: A1- para o entrevistado 1; A2 para o entrevistado 2, e assim sucessivamente.

Рага o tratamento e análise dos dados, utilizamos como referencial a Análise de Conteúdo modalidade de análise temática. Esta modalidade se fundamenta no tema, que por sua vez está ligado a uma afirmação a respeito de um assunto, podendo ser representado por meio de palavras, resumos ou frases, desvelando-se assim núcleos de sentido, cuja frequência ou presença tem alguma representação para o objeto estabelecido. Tomamos como referência o tema enquanto uma "unidade de significação que se libera naturalmente de um texto, analisado segundo critérios relativos à teoria que serve de guia à leitura"(15).

Desta forma, os núcleos temáticos sistematizados que analisamos nesse trabalho foram: contextualização da época da adolescência e controle da sexualidade, com os subtemas: diálogo, medicalização e religião.

Cabe ressaltar que a proposta do referido estudo foi submetida à análise e aprovada pelo Comitê de Ética em Pesquisa da Universidade de Franca (Unifran), protocolo n.011/2011.

\section{RESULTADOS E DISCUSSÃO}

Participaram da pesquisa, quatro pais, os quais tinham idade variável entre 44 e 53 anos e quanto as profissões eram médico, engenheiro, industrial e professor universitário. Os filhos do sexo masculino, tinham idade variando entre 15 e 18 anos. 
Para esta etapa da pesquisa, utilizamos como referencial teórico, um autor que pensamos, discute com maestria a sexualidade humana, Michael Foucault.

\section{Contextualização da época da adolescência}

Nesse núcleo de sentido percebemos que os pais dos adolescentes, ao falarem da própria adolescência, acharam por bem contextualizá-la em uma época, como que para desculpar possíveis erros que possam ter ocorrido, como podemos ler nas falas a seguir:

Adolescência é considerada por parâmetros da época... ele (pessoa que se encontrava no lugar do pai) tentou passar aquilo que ele poderia fazer de melhor na época. (A1)

A contextualização tanto aparece de forma manifesta, como latente quando outro pai fala de suas vivências, das possíveis orientações que poderia ter tido, somente na negativa, como se dissesse o tempo todo: "Naquela época era assim...", denotando certo fatalismo. A fala parece um desabafo, pois de certa forma o homem adulto de hoje recrimina sua própria adolescência, sem perceber que na época, o que hoje seria considerado um erro, foi vivenciado com certo prazer. Verificamos isso, então, na fala do A2 quando relatam:

Foi uma coisa (a sexualidade) que eu tinha vamos dizer muita curiosidade, né? Por exatamente não ter tido uma... instrução com os meus pais sobre esse assunto, né? Nem da minha mãe, nem do meu pai, então foi uma coisa que eu procurei descobrir por mim mesmo, sem perguntar para as pessoas.

Esse mesmo entrevistado relata:

$A$ adolescência do meu filho está sendo bem melhor que a minha.

Épocas diferentes, contextos diferentes, a comparação tem um "quê" de pré-fabricada, pois se espera que ele pense que o que está sendo oferecido para o filho é de melhor qualidade do que o que recebeu, e quase sempre isso está referendado em uma maior participação que ele tem na vida do filho.

Desde o início dos anos 80, a ideia de "novos pais" teve um sucesso crescente em inúmeros países ocidentais, a ponto de se tornar um conceito ordinário ao se falar em evolução das mentalidades masculinas, começou a se observar, mais detalhadamente as novas relações que estavam ocorrendo entre pais e filhos ${ }^{(17)}$.

Mas é muito interessante percebermos que esse pai quando se refere à própria adolescência, não vê na ausência do pai um mal, um sacrifício e sim um certo alívio:

Eu tive uma adolescência, vamos dizer tranquila, longe dos pais, né? Vivi aqui longe dos pais, não foi conturbada (A2).

Ora, percebemos o quanto a comparação é difícil. No momento, provavelmente, com toda a pressão para que um pai seja participante, ele acha que se ele se ausentasse seria muito ruim para os filhos, mas na época em que ele foi filho, não eram essas as regras do jogo e, portanto, ter o pai longe era uma forma de usufruir um pouco mais de liberdade e não motivo para desenvolver problemas emocionais pela ausência do pai.

Isso fica ainda mais claro, quando mais tarde na entrevista percebemos que ele como pai não gosta de falar tanto com o filho; o que acaba acontecendo é que esse filho faz parte de uma época em que conversar com o pai sobre sexo está dentro de certo "script" e, portanto, é o filho dessa época que solicita o tão "famigerado" diálogo:

A gente tem conversas sobre isso (sexo), né? Principalmente até mais da parte dele do que da minha, ele que procura me envolver mais, ele que procura perguntar, a querer descobrir as coisas, eu falo, mas eu falo pouco, né?(A 2).

O pai A3 trás à tona as mesmas observações, considera pequena sua participação no contato com a sexualidade do filho, perto do que se imagina que deveria ser nos dias de hoje. Também aqui quem o procura é o filho:

É... é uma participação que chega a ser tão pequena, porque mais ele participa a mim do que eu a ele. (A3)

Mas em seguida se coloca como um pai moderno, de sua época:

A minha participação mais é no sentido de orientação, de como usar o preservativo, né? (A3)

A sexualidade continua sendo um assunto delicado e difícil entre pais e filhos. É uma área onde se encontram 
as inseguranças e o medo com relação ao outro. Conversar sobre sexo, requer uma relação de franqueza, intimidade e confiança. A sexualidade é tema que cada vez mais deve fazer parte do diálogo entre pais e filhos, uma forma de diminuir a falta de informação e o desconhecimento sobre a mesma, estabelecer valores próprios de cada família, estimulando o conhecimento de si e do outro(12)

Também esse entrevistado não vê com maus olhos a falta de diálogo com o pai dele:

Na época a gente aprendia muito na rua, né? A gente aprendia na escola, com os amigos, conversando na parte da sexualidade, conversando na parte do sexo, entendeu? (A3)

Observamos que a falta da participação do pai não fez falta na adolescência desse entrevistado, mas isso foi no passado; hoje é preciso conversar, dialogar ${ }^{(11-12)}$.

Mas esse mesmo entrevistado quando fala sobre o pai parece sentir-se na obrigação de avaliá-lo. Esquece-se então que essa ausência de diálogo não foi traumatizante e entra em cena a condenação. É importante ressaltar que esta condenação é a que seria "natural" e esperada para os dias de hoje e não na época do acontecimento:

A participação do meu pai é praticamente zero, né? ...meu pai era muito fechado nesse sentido, né?... então, na realidade nunca teve um bate-papo ou nunca teve um diálogo sobre a sexualidade, na época, do papai comigo. (A3)

Novamente surge a comparação, com um juízo de valores, equiparando épocas diferentes:

Então, essa sexualidade, ela é muito mais fácil hoje do que era no nosso tempo, né? Eles se divertem, né, entre ( ), na própria comunidade. E nós não, antigamente a gente tinha que procurar mulher de bordel (risos). (A3)

Será que na época, era ruim ir ao bordel? Será que na época atual é tão tranquilo "transar" na própria comunidade? O que é mais fácil? Isso ficará mais claro quando o núcleo temático "controle da sexualidade" for discutido.
O A4 vem corroborar de uma maneira interessante nessa discussão de uma contextualização da época da adolescência:

...então foi isso aí, descobri tudo sozinho, não tive ajuda de ninguém.

As falas dos atores sociais referem-se à ausência de seus pais no período da adolescência. Neste sentido observamos que foi em determinado período histórico (século XVIII) que o sexo dos adolescentes passou a ser um importante alvo de práticas institucionais que mereciam especial atenção de pais e pedagogos ${ }^{(9)}$.

Já os filhos dos entrevistados, claramente, são frutos de uma época que concebe a adolescência como uma etapa especial do desenvolvimento que pressupõe cuidados, atenção, cerceamentos e, sobretudo, a presença vigilante de pais e educadores.

Neste sentido, é possível estabelecer que adolescentes que recebem orientações dos pais ou da escola apresentam menos comportamentos de risco. O diálogo sobre sexualidade com os pais é um item considerado importante do ponto de vista de educação sexual aos adolescentes ${ }^{(18)}$

Que cada época produz verdades diferentes parece ter ficado claro nessa análise da contextualização. O que foi bom em uma época, se avaliado com o olhar de outro período histórico, poderá sofrer condenações inimagináveis. Desta forma, assim como há necessidade de se produzir riquezas, há também de se produzir a verdade, e verdade na visão Foucaultiana quer dizer um conjunto de regras segundo as quais se distingue o verdadeiro do falso e se atribuem ao verdadeiro, efeitos específicos do poder ${ }^{(19)}$. Isto é, se determina o que será verdadeiro de acordo com as necessidades do poder daquela época. Podemos dizer que a verdade é construída, não sendo então um fenômeno natural(20).

\section{Controle da sexualidade}

O presente núcleo procurou retratar formas de regulação dos aspectos sexuais por meio dos seguintes subtemas: diálogo, medicalização e religião.

\section{Diálogo}

O "controle da sexualidade" envolve aspectos tanto das relações dos pais dos adolescentes com seus pais, quanto com seus filhos adolescentes, sendo que muitas 
vezes o que se observa numa aparente mudança possa ser apenas o reverso da mesma moeda.

Em um primeiro momento, o diálogo antes inexistente é hoje quase obrigatório nessa classe social, poderia apontar para uma evolução inquestionável no papel do pai e na própria vivência da sexualidade em nossa época, mas é necessário aprofundar esse olhar. Hoje os pais estão preocupados ou pelo menos mais interessados em conseguir manter um diálogo com seus filhos. Não podemos ignorar que a AIDS, as doenças sexualmente transmissíveis e as drogas são molas propulsoras para uma nova possibilidade de relacionamento entre pais e filhos ${ }^{(13)}$.

No entanto, na condução de qualquer entrevista com os adolescentes, eles não se mostram mais seguros quanto a suas experiências sexuais e muito menos, mais responsáveis quanto a uma série de fatores que envolvem as mesmas (descoberta do próprio corpo, do prazer, do amor, até mesmo de uma transcendência possível de ser experimentada na vivência da sexualidade). Mas isso está fora de cogitação, pois nenhum pai se propõe a conversar com os filhos adolescentes nestes termos; ensina-os a usar preservativos, como se isso fosse o máximo em termos de orientação, além do que os filhos conversam menos com seus pais sobre sexo em relação ao diálogo com suas mães ${ }^{(11-12,18)}$.

Poderíamos pensar em evolução, também no sentido de que o que antes era proibido, hoje é permitido e, muitas vezes, até incentivado a ser dito. Não se deve calar sobre nada. Vejamos o que o A1 tem a dizer:

É hoje, com certeza, de uma maneira muito delicada, basicamente todas as vezes que meus filhos saem de casa, eles chegam, nós temos um bate papo de respeito de como foi o passeio. O que aconteceu. O que deixou de acontecere não existe repressão, porque se você reprimir, você vai perder a confiança, não tem jeito, então você tem que saber exatamente tudo aquilo que está acontecendo para você tentar orientá-lo da melhor maneira possivel.

Este relato nos afirma que não existe repressão. Será que não? Uma investigação minuciosa sobre tudo o que o filho faz ou deixa de fazer, não seria uma das formas mais poderosa, sutil e cruel de controle?

Os adolescentes são solicitados a falar e a falar cada vez mais sobre sua sexualidade (algo que lembra um confessionário do século XIX). Sua vivência passa por uma avaliação do pai, que finge não estar avaliando para poder saber mais, senão o filho pode recuar e se calar. Saber esse que the dá poder para "orientar" o filho da forma que considerar mais "útil" para o futuro do filho. Essa "utilidade" quase sempre está mais ligada a um funcionalismo do que a um prazer ao qual o filho possa almejar.

Isto posto, reiteramos que o jogo do poder existente na relação apresentada por esse pai não consiste em demarcar o certo ou errado, o lícito ou ilícito, e, muito menos, implica em algum tipo de condenação, a ordem agora é gerir a sexualidade dentro de um sistema de utilidade $^{(9)}$. Assim, "o sexo não se julga, administra-se"(9).

Mas, nesse jogo de relações, não deve haver condenações, os pais também estão tentando "funcionar" bem (funcionar aqui tem um sentido de estar colaborando рага que uma engrenagem maior, da qual se sentem apenas uma peça, funcione). O A3 chega a dizer:

Ele tá percebendo que o pai não é pai, o pai tá querendo ser amigo. Mas eu ainda não consegui demonstrar essa amizade, essa relação de que eu não quero ser pai dele, eu quero ser amigo dele.

A fala anterior nos mostra que a autoridade de pai foi rompida, o que segundo uma outra declaração do mesmo entrevistado parece ser possível, graças a uma infantilização do pai em questão:

Eu vou levando na brincadeira, eu vou conversando é... como se todo mundo tivesse brincando é... fica mais fácil. (A3)

Então se pode inferir que a conversa não é assim tão fluída, mas precisa de artifícios para poder se falar sobre sexo. Sexo deixou de ser tabu ou estamos tendo que enfrentar um agravante a mais? Não só continua sendo tabu, como ainda nos sentimos na obrigação de disfarçar isso e parecermos todos mais liberados: antes era tabu e pronto! Cabia aos adolescentes trilhar caminhos, muitas vezes criativos, entre seus pares, para o enfrentamento necessário de um obstáculo visível, quase palpável. E hoje? O que fazer com um tabu maquiado por longas conversas que, ao que tudo indica, incitam uma "falação" a respeito do assunto, que muitas vezes esgota-se no próprio ato de ser livre para falar nesse assunto proibido, 
intimidador, ainda permeado pelo medo e pela dificuldade em comunicá-lo ${ }^{(11-12,14,18)}$.

Mas fica a questão: essas conversas propiciam romper com o proibido na vivência da sexualidade, que é a ponta de um iceberg, ou essa vivência necessitaria de uma liberdade conquistada também em outros aspectos da constituição do ser, que encontram-se na parte submersa na água? Não estaríamos correndo o risco de tratar com tanta eloquência a parte aparente e, no caso do oceano da vida mexer suas águas, essa ponta aparente submerge e aparecem outras, com as quais os adolescentes nem sequer têm um mínimo de intimidade?

Esse tema se relaciona a partir da compreensão de que a repressão possui uma estreita ligação com o poder, o saber e a sexualidade ${ }^{(9)}$. Não resolve um pai se infantilizar para falar com o filho, não adianta "fingir" que se está rompendo com um tipo de poder, quando na verdade não se está.

Poder, saber e sexualidade formam um tripé que sustentam certa ordem das coisas, para realmente liberarse da repressão dessa ordem faz-se necessário que muito mais do que a sexualidade entre em jogo. Do contrário corremos risco de nos distrairmos em demasiado em longos colóquios sexuais, quando as discussões que realmente poderiam nos libertar em outros aspectos e também no sexual, ficam totalmente esquecidos, submersas na profundidade do oceano. Desta forma "a menor eclosão de verdade é condicionada politicamente"(9). Nossa sexualidade, nosso corpo, nossas condutas também parecem ser politicamente condicionadas.

O A4, diz conversar o máximo sobre sexualidade com os filhos, mas não tem coragem de saber se a primeira relação sexual aconteceu:

Na parte relativa ao sexo, eu tento conversar o máximo que pode né? Só que a gente ainda não conversou claramente se eles tiveram ou não a primeira trans, eu ainda não tive coragem de perguntar isso a eles. E nem eles me falaram. Mas pelo achado de camisinha nos armários é bem provável que tenha tido a primeira vez. (A4)

A questão aqui colocada se refere ao que é próprio das sociedades modernas que não condenaram o sexo a permanecer na obscuridade, mas sim se devotaram a falar dele sempre, valorizando-o como um segredo(9).
Tanta intimidade, tanta conversa, nada precisa ser oculto, fala-se o máximo, mas no final resgata-se a ideia do segredo, do que dá medo, do que intimida.

E depois, sem meias palavras mostra o quanto de repressão existe nesse diálogo aberto, quando diz:

Hoje a gente tá mudando o diálogo. E se eles forem "nhanhá" os cuidados que têm que tomar. Isso é conversado na mesa mesmo de refeição. Eu acredito que ninguém na minha casa vai ser pai ou mãe sem querer. Falar "Oh aconteceu, pegou a gente de surpresa, eu não sabia". Isso daí, eu acho que não... Se acontecer... eles não podem falar que não sabiam. Então é bem consciente. (A4)

Quer dizer o "papo" é válido enquanto suas orientações forem seguidas à risca, ninguém poderá dizer que ele (pai) não avisou, não preveniu antes. Alguém conhece um tipo de controle mais perverso do que aquele que quando você se encontra em dificuldades, o outro the aponta o dedo e diz: "-Não falei? Bem que eu avisei."

\section{Medicalização}

Outro fator que merece ser discutido no núcleo temático "Controle da Sexualidade", é o uso de certo saber científico que os pais utilizam em suas conversas sobre sexualidade com seus filhos adolescentes. Vamos estar nos referindo a esse aspecto, como medicalização do $\operatorname{sex} 0^{(9)}$.

Alguns depoimentos mostram que os entrevistados, em suas conversas sobre sexualidade com os filhos, sempre a ligam a duas consequências desastrosas: doença e gravidez indesejada:

Por isso que eu ensino muito o $L$, a pessoa ter relacionamento sexual com preservativo, tá? Primeiro para você evitar doença sexualmente transmissivel, segundo para evitar gravidez. (A3). O medo hoje, nas experiências sexuais deles seria: primeira coisa são as doenças, que a gente procura falar sobre as doenças sexualmente transmissiveis. $O$ principal meu é a paternidade irresponsável. (A4)

Percebemos que se evita falar da sexualidade que incomoda, que constrange, que colocaria também o pai como um ser sexualizado, por meio da orientação de métodos contraceptivos que evitariam não só a gravidez, como também as DSTs/aids (Doenças Sexualmente 
Transmissíveis/ Síndrome da imunodeficiência adquirida). Para tanto, deve ser encorajado o diálogo entre os pares e família, рагa que as questões de gênero sejam desmistificadas, para que se favoreça a ação e reflexão, acerca da vulnerabilidade adolescente frente às DST/aids, e empoderamento frente aos agravos relacionados à saúde sexual e reprodutiva(21).

Embora em nenhum momento estejamos deixando de lado a importância de uma orientação que evite as DSTs , não podemos em nome disso, deixar de discutir o quanto é estranho a ligação do prazer sexual com a doença e também com uma série de orientações assépticas, higiênicas e profiláticas quanto à melhor maneira de se evitar os desmandos do corpo e da alma quanto à vivência da sexualidade, que a medicina a partir do século XIX, avalia e esmiúça para então chegar ao veredicto de que o sujeito é normal ou não.

Nessa perspectiva fica enfatizado que esse mecanismo apontando para o fato de que ao se falar de sexo, sob o ponto de vista neutro da ciência, pode estar se esquivando de falar sobre o mesmo propriamente dito. Assim, medos e patologias novas são instauradas, mas junto se acopla a promessa de que se seguindo todas as maneiras de higiene e assepsia que são oferecidas, ficarse-á livre de todos os perigos ${ }^{(9)}$.

Esse controle está obviamente comprometido com o poder, pois primeiro se cria o perigo e depois se apresenta a forma de se salvar dessa ameaça. Controle, poder, saber e sexualidade continuam intimamente ligados ${ }^{(9)}$.

Normal e tranquilo, estes também foram termos utilizados pelos entrevistados para referirem-se à própria adolescência ou à adolescência do filho:

A minha adolescência até que foi uma adolescência meio tranquila.(A2). O meu filho é uma pessoa assim, muito tranquila e normal. (A3)

Se lembrarmos que vários autores definiram a adolescência como um período turbulento, de conflito, o que será que esses entrevistados querem dizer com "tranquilo"?

Foi tranquila porque foi turbulenta e, portanto, aconteceu o que se esperava na vivência da adolescência; ou foi tranquila porque o adolescente não apresentou conflitos, não fez ruídos, não causou problemas? Mas se assim foi, corre-se o risco dele não ter vivido o que se faz necessário experimentar na adolescência segundo os estudiosos do tema.

Ao que parece "tranquilo" para nossos entrevistados é mais uma dessas palavras, que podem dizer muita coisa, mas devido à amplitude de sentido, o que acabam fazendo é ocultando o que seria difícil de falar. Não que os entrevistados tenham problema de vocabulário, mas o que pensam do filho adolescente tem que passar por um "crivo ideológico" tão forte que, no geral, esse anteparo não permite que eles vejam os adolescentes com suas particularidades, suas vivências concretas, às vezes únicas; então, fica difícil dizer algo mais do que "tranquila".

Muitas vezes nosso discurso (sobretudo o médico), é mais servil do que libertador; segundo suas próprias palavras "é mais servil ante as potências da ordem do que dócil às exigências da verdade" (9).

\section{Religião}

Embora apenas um ator social tenha falado sobre religião explicitamente, achamos por bem comentá-la, pois existem temas que saltam aos olhos mesmo que em uma única entrevista ${ }^{(15)}$

Iniciamos, então, essa discussão com as frases ditas pelo $A 1$, sobre aspectos diretamente ligados à Religião, referentes à sua adolescência:

A preocupação baseava-se primeiro em pecado, né? Que era uma coisa proibida o contato com o sexo. (A1) ...mas o que ficou, a imagem realmente ficou uma imagem de repressão, uma imagem de pecado, que não deveria fazer aquilo, que aquilo era errado.(A1)

Esse mesmo entrevistado afirma ter feito o inverso com o filho.

Eu consegui apagar da cabeça dele aquela ideia de pecado, de fruto proibido mas com muita responsabilidade, sempre dizendo para ele, para ele não tomar alguma atitude que não gostaria que outros tomassem aquela mesma atitude com a família dele. Sempre respeitando, se possivel respeitando o máximo. (A1) Primeiro lugar acabar com a ideia de pecado. Segundo lugar ter a ideia de respeito ao próximo. (A1)

O mais interessante nessa entrevista é perceber o quanto a religião deixou marcas profundas nesse 
entrevistado, que parece querer livrar-se da ideia de pecado ao exorcizar, na educação do filho, os seus próprios demônios. Foi para ele, pai, que a religião e o pecado tiveram tanta importância, e não para o filho.

Mas, ele pensa que não basta não incutir essa culpa religiosa no filho. Ele faz um estranho caminho; primeiro, ele conta para o filho que o pecado existe, para depois dizer que não é preciso se preocupar com essa ideia de pecado.

Também, o vocabulário usado por esse entrevistado é marcantemente de cunho religioso: "omissão", "atos", "respeito ao próximo", chegando em um certo momento a lembrar o "Ato de Contrição": "...por pensamentos e palavras, atos e omissões. Por minha culpa, minha tão grande culpa..."

O respeito ao próximo, o "não fazer com o outro o que não quer que façam com você", são jargões não só morais, mas também religiosos. Esse entrevistado mudou a "embalagem", mas o conteúdo continua o mesmo e, provavelmente, só não causará o mesmo efeito de culpa religiosa em seus filhos, porque a situação que os circunscreve é outra e não porque o pai os "salvou" de tal sorte. Até mesmo essa ideia de "salvação" está intimamente ligada à questão religiosa da qual o entrevistado não consegue desvencilhar-se.

Assim, pais como sujeitos do cotidiano, estabelecem o ser e o agir mobilizados por contextos intersubjetivos e estabelecendo diálogos entre discursos distintos sobre sexualidade, religiosidade e educação de seus filhos, interpretando e recriando estes distintos discursos ${ }^{(22)}$.

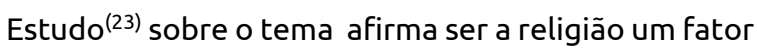
muitas vezes determinante quando se fala em vida sexual. Relata que, adolescentes que têm uma religiosidade tem uma tendência a esperar mais para iniciar sua vida sexual. Praticantes ou não, sabe-se que a religião é fator marcante nas escolhas, condutas e reações que o ser humano tem, o que na adolescência, não seria diferente. Porém, ao que tudo indica a repressão e o poder só mudam de mãos ${ }^{(9)}$.

Ao invés do controle ser regido por um rígido código religioso, é agora sutilmente submetido a um novo arranjo, onde se procura um comedimento capaz de mascarar a violência presente em qualquer punição(9).

Achamos relevante apontar que é desse mesmo pai, a primeira fala constante no núcleo temático "Controle da Sexualidade", que faz do retorno do filho à casa depois de uma noite de passeio, uma verdadeira confissão.

\section{CONCLUSÃO}

Nesta investigação verificamos que a sexualidade continua sendo um assunto polêmico, que suporta olhares e interpretações diferentes a seu respeito.

Constatamos que pouco pode ser dito especificamente quanto ao gênero masculino, isto é, percebe-se que os homens estão mais participantes na educação dos filhos até mesmo porque, é esse o modelo de pai ideal nos dias de hoje, fato diferente do que acontecia com os pais dos entrevistados, que praticamente não participavam diretamente da educação dos filhos.

Notamos então, que a sexualidade, o tipo de relação entre pai e filho são frutos de uma época, talvez seja essa a razão para que em $100 \%$ dos casos houvesse uma mudança tão visível e radical: antes não se falava com os pais sobre sexo, agora é necessário falar tudo o que se pensa para os pais.

Sobre se dizer tudo o que se pensa, percebemos que essa ausência de espaço para o segredo, tem sido um entrave no desenvolvimento dos adolescentes, muito mais que uma ajuda. Poderíamos dizer que com esse excesso de diálogo estamos correndo o risco de regredir em termos de educação, inclusive na sexual.

Antigamente, quando a criança ia para a escola, isso significava se distanciar por um tempo dos olhos dos pais. Mas o que acontece hoje em dia? A participação dos pais, inclusive forçadamente a do pai na escola se tornou importantíssima. Assim, os olhos dos adultos penetram em um ambiente que antes era do domínio da criança. Quando a adolescência chega, esse caminho de ser diferente do que os pais querem, já foi cerceado. Os adolescentes não resistem aos interrogatórios com os quais os pais os interpelam, sentem-se até mesmo mais seguros falando tudo o que pensam, porém essa segurança é falsa. Regridem a uma condição infantil e o que é pior, geralmente se encontram com pais infantilizados, que também não sabem o que fazer e na dúvida fazem o que a "moda" do momento dita.

Uma conhecida propaganda de pomada nos diz que "não basta ser pai; tem que participar". Não podemos deixar de usá-la para fechar nossa discussão sobre medicalização da sexualidade. Como podemos perceber, até a relação pai e filho passa pelo uso de uma pomada. Talvez isso sirva para elucidar de uma forma metafórica o que foi discutido neste trabalho quanto à medicalização da sexualidade. É certo que muitas vezes uma pomada 
pode curar, mas também sabemos que às vezes ela serve para ocultar a "ferida", que se antes não for debridada e limpa, pode vir a infeccionar.

Não estamos com isso dizendo que as discussões que envolvem a sexualidade, principalmente, a dos

\section{REFERÊNCIAS}

1. Saito MI, Silva LEV. Adolescência: prevenção e risco. 2a ed. São Paulo: Atheneu; 2007.

2. Ayres JRCM, França Júnior I, Calazans GJ, Saletti Filho HC. O conceito de vulnerabilidade e as práticas de saúde: novas perspectivas e desafios. In: Czeresnia D, Freitas CN. Promoção da saúde: conceitos, reflexões, tendências. Rio de Janeiro: Fiocruz; 2003. p. 117-40.

3. Guimarães BE. Gravidez na adolescência: fatores de risco. In: Saito MI, Silva EV. Adolescência: prevenção e risco. 2a ed. São Paulo: Atheneu; 2007. p. 295-6.

4. Conn C. Young African women must have empowering and receptive social environments for HIV prevention. AIDS Care [Internet]. 2013 [acesso em: 30 set 2013];25(3):273-80. Disponível em:

http://dx.doi.org/10.1080/09540121.2012.712659.

5. Hensel DJ, Fortenberry JD. A multidimensional model of sexual health and sexual and prevention behavior among adolescent women. J Adolesc Health [Internet]. 2013 [acesso em: 30 set 2013];52(2):219-27. Disponível em:

http://dx.doi.org/10.1016/j.jadohealth.2012.05.017.

6. Graves KN, Sentner A, Workman J, Mackey W. Building positive life skills the Smart Girls way: evaluation of a schoolbased sexual responsibility program for adolescent girls. Health Promot Pract [Internet]. 2011 [acesso em: 30 set 2013];12(3):463-71. Disponível em: http://dx.doi.org/10.1177/1524839910370420.

7. Fernandes AO, Santos Júnior HPO, Gualda DMR. Adolescent pregnancy: perceptions of mothers of young pregnant women. Acta paul. enferm. [Internet]. 2012 [acesso em: 30 set 2013];25(1):55-60. Disponível em: http://dx.doi.org/10.1590/S0103-21002012000100010. 8. Almeida Mda C, Aquino EM. Adolescent pregnancy and completion of basic education: a study of young people in three state capital cities in Brazil. Cad Saude Publica [Internet]. 2011 [acesso em: 23 set 2013];27(12):2386-400. Disponível em: http://dx.doi.org/10.1590/S0102-311X2011001200010.

9. Foucault M. História da sexualidade: a vontade de saber. 8a ed. Rio de Janeiro: Graal; 1985.

10. Meincke SMK, Carraro TE. Vivência da paternidade na adolescência: sentimentos expressos pela família do pai adolescente. Texto Contexto Enferm [Internet]. 2009 [acesso em: 30 set 2013];18(1):83-91. Disponivel em: http://dx.doi.org/10.1590/S0104-07072009000100010. 11. Jones DE. Diálogos entre padres y adolescentes sobre sexualidad: discursos morales y médicos en la reproducción de las desigualdades de género. Interface (Botucatu) [Internet]. 2010 [acesso em: 30 set 2013];14(32):171-82. Disponível em: http://dx.doi.org/10.1590/S1414-32832010000100014.

12. Almeida ACCH, Centa ML. A família e a educação sexual dos filhos: implicações para a enfermagem. Acta paul. enferm. [Internet]. 2009 [acesso em: 30 set 2013];22(1);71-6. Disponível em: http://dx.doi.org/10.1590/S0103-21002009000100012. 13. Cano MAT, Bichuette M, Zaia J. A freqüência de partos de adolescentes em uma cidade do interior paulista. Nursing. 2011;3(18):19-23.

14. Paiva V, Aranha F, Bastos FI. Opiniões e atitudes em relação à sexualidade: pesquisa de âmbito nacional, Brasil 2005. Rev adolescentes, que vivem um período conturbado de suas vidas, não sejam válidas; apenas ousamos apontar o perigo de estarmos ensinando como se faz, sem termos a coragem de discutir o que se está fazendo.

Saude Publica [Internet]. 2008 [acesso em: 30 set 2013];42(Suppl. 1):54-64. Disponível em: http://dx.doi.org/10.1590/S0034-89102008000800008. 15. Minayo MCS. O desafio do conhecimento: pesquisa qualitativa em saúde. 9a. ed. Revisada. São Paulo: Hucitec; 2010. 16. Fontanella BJB, Ricas J, Turato ER. Amostragem por saturação em pesquisas qualitativas em saúde: contribuições teóricas. Cad Saude Publica [Internet]. 2008 [acesso em: 30 set 2013];24(1):17-27. Disponível em: http://dx.doi.org/10.1590/S0102-311X2008000100003. 17. Devreux AM. A paternidade na França: entre igualização dos direitos parentais e lutas ligadas às relações sociais de sexo. Soc. estado. [Internet]. 2006 [acesso em: 30 set 2013];21(3):607-24. Disponível em: http://dx.doi.org/10.1590/S0102-69922006000300003. 18. Borges ALV, Nichiata LYI, Schor N. Conversando sobre sexo: a rede sociofamiliar como base de promoção da saúde sexual $e$ reprodutiva de adolescentes. Rev Lat Am Enfermagem [Internet]. 2006 [acesso em: 30 set 2013];14(3):422-7. Disponível em: http://dx.doi.org/10.1590/S0104-11692006000300017. 19. Foucault M. Doença mental e psicologia. Rio de Janeiro: Tempo brasileiro; 1979.

20. Candiotto C. Foucault: uma história crítica da verdade. Trans/Form/Ação [Internet]. 2006 [acesso em: 30 set 2013];29(2):65-78. Disponível em:

http://dx.doi.org/10.1590/S0101-31732006000200006.

21. Santos ACL, Gubert FA, Vieira NFC, Pinheiro PNC, Barbosa SM. Modelo de crenças em saúde e vulnerabilidade ao HIV: percepções de adolescentes em Fortaleza-CE. Rev. Eletr. Enf. [Internet]. 2010 [acesso em: 23 set 2013];12(4):705-10. Disponível em: http://dx.doi.org/10.5216/ree.v12i4.6492. 22. Silva CG, Santos AO, Licciardi DC, Paiva V. Religiosidade, juventude e sexualidade: entre a autonomia e a rigidez. Psicol Estud [Internet]. 2008 [acesso em: 30 set 2013];13(4):683-92. Disponivel em: http://dx.doi.org/10.1590/S141373722008000400006.

23. Leite IC, Rodrigues RN, Fonseca MC. Fatores associados com o comportamento sexual e reprodutivo entre adolescentes das regiões Sudeste e Nordeste do Brasil. Cad Saude Publica [Internet]. 2004 [acesso em: 23 set 2013];20(2):474-81. Disponivel em: http://dx.doi.org/10.1590/S0102311X2004000200015.

Artigo recebido em 08/11/2012.

Aprovado para publicação em 15/08/2013.

Artigo publicado em 30/09/2013. 